\title{
EFFECT OF MINERAL MATTER ON PRODUCT YIELD AND COMPOSITION AT ISOTHERMAL PYROLYSIS OF TURKISH OIL SHALES
}

\author{
M. SERT* ${ }^{*}$ L. BALLICE, M. YÜKSEL, M. SAĞLAM \\ Ege University, Department of Chemical Engineering \\ Bornova (35100) Izmir, Turkey
}

\begin{abstract}
This study was aimed to investigate the effect of mineral matter of Göynük oil shales (GOS) on pyrolysis and product evolution. Organic part was separated from mineral matter before pyrolysis in an isothermal pyrolysis reactor. In the demineralization step, carbonate, pyrite and silicates were removed from kerogen by using $\mathrm{HCl}, \mathrm{HNO}_{3}$ and $\mathrm{HF}$, respectively. Thereafter all samples were pyrolized in an isothermal pyrolysis apparatus. The temperatures for pyrolysis experiments were 450, 500, 550, 600, $650{ }^{\circ} \mathrm{C}$. Recoveries of volatiles and total hydrocarbons increased with increasing temperature. At pyrolysis of silicate-free oil shale (GOS-F), volatile hydrocarbon recovery (VHR) increased nearly by $10 \mathrm{wt}$ \% as compared with VHR from raw oil shale sample (GOS-R) at each pyrolysis temperature. Carbon content of solid residue was also calculated. The effect of mineral content of oil shale on product yield and composition was determined by establishing carbon balance in the reactor. The amount of solid residue decreased as a function of demineralization degree. The pyrolysis reaction in the presence of silicate mineral showed the catalytic effect of silicate minerals aiding coking reactions, and carbon deposition decreased averagely by $20 \mathrm{wt} . \%$ in silicatefree oil shale compared with the value for GOS-R at each temperature.
\end{abstract}

\section{Introduction}

Increasing demand for hydrocarbons both for fuels and for chemical feedstocks and the awareness of the finite nature of petroleum deposits results in great interest in alternate sources of fossil fuel. Oil shale represents the main source of solid fossil hydrocarbon compounds $\left(10 \cdot 10^{15} \mathrm{t}\right)$ in the form of kerogen on earth. Oil can be obtained from kerogen by pyrolysis and retorting processes. The estimated amount of oil recoverable from oil shale is much higher than the resources of crude oil. With an increasing demand

\footnotetext{
* Corresponding author: e-mail murat.sert@ege.edu.tr
} 
for oil followed by a high crude oil price, the worldwide demand of valorization of oil shale will be very important in the future [1].

Oil shale deposits in Turkey are widely distributed in the middle east and western Anatolian [2]. The oil shales in Turkey, such as Seyitömer-Kütahya, Beypazarı-Ankara, Himmetoğlu-Bolu, Hatıldağ-Bolu, Hatıldağ oil shale field in the southeastern Göynük-Bolu, and Mengen-Bolu, are generally of Middle-Upper Miocene age [3].

Oil shale is a complex mixture of organic and inorganic components. Oil shale rocks consist of marl and clays, in which organic matter is heterogeneously and finely dispersed [2]. Kerogen and bitumen comprise the organic part of oil shale. Bitumen is only a small fraction of the organic part and it is soluble in ordinary solvents. Kerogen is the insoluble part of organic material and composed mainly of carbon, hydrogen and oxygen with minor amounts of nitrogen and sulfur. Hydrocarbons are released as vapor when kerogen is subjected to a temperature between 300 and $660{ }^{\circ} \mathrm{C}$ in the absence of oxygen $[4,5]$.

The fate of inorganic elements at pyrolysis and catalytic effects of mineral matter require investigation [6]. The inorganic part consists mainly of quartz, clay, different types of carbonates $\left(\mathrm{CaCO}_{3}, \mathrm{MgCO}_{3}\right.$ and dolomite), pyrite and $\mathrm{Fe}_{2} \mathrm{O}_{3}$, as well as trace elements (As, B, Mo, Ni and $\mathrm{Zn}$ ) [7]. As the organic matter (kerogen) is finely distributed in oil shale inorganic matrix, mineral matter plays an important role in kerogen decomposition [8]. Therefore, the effect of mineral matter and the interaction between kerogen and the inorganic matrix during reactions are important for the kerogen pyrolysis process.

Isolation of kerogen can be obtained with physical or chemical methods. Chemical methods are based on digestion of inorganic parts by means of acid treatment. Generally, acid treatment using $\mathrm{HCl}$ and $\mathrm{HF}$ does not alter the structure of kerogen. However, nitric acid which is known to be a strong oxidizing agent alters the kerogen by increasing nitrogen and oxygen content with the introduction of carboxylic groups into the structure of kerogen [9].

There are many studies in literature indicating that treatment by the mixture of concentrated $\mathrm{HCl}$ and $\mathrm{HF}$ acids has been successfully used to remove carbonate, sulfate, clay minerals, quartz and silicates [9-11].

As proved by the previous results, leaching of mineral matter with $\mathrm{HCl}$ caused a slight decrease in conversion to volatile hydrocarbons but the removal of pyrites with $\mathrm{HNO}_{3}$ did not affect the reactivity of the organic material at the temperature-programmed pyrolysis of Göynük oil shale [6].

Besides these works, studies on the effect of mineral matter on the pyrolytic behavior of kerogen are scarce in literature. To the best of our knowledge, no study has been reported on the effect of mineral matter on the product yield at isothermal pyrolysis of Göynük oil shale. In this study, the composition of volatile products was determined and also the effect of the mineral content of oil shale on product yield and composition was determined by establishing carbon balance in reactor. The effect of mineral 
matter of oil shale on conversion of organic carbon into volatile hydrocarbons, carbon in solid residue and total hydrocarbon recovery were investigated. The distribution of straight-chain paraffins and olefins was calculated.

\section{Experimental}

\section{Samples}

In this study, oil shale samples were obtained from Göynük oil shale (GOS) deposit near the town of Bolu in northwestern Turkey. For the experiments, the sample was sieved to obtain a $<0.1 \mathrm{~mm}$ fraction. Elemental analysis of oil shales is given in Table 1 . All chemicals $\left(\mathrm{HCl}, \mathrm{HNO}_{3}\right.$ and $\left.\mathrm{HF}\right)$ used in this study were of analytical grade. The samples obtained at each demineralization step were labeled as GOS-R for raw, GOS-C for carbonatefree, GOS-N for pyrite-free and GOS-F for silicate free oil shale as used in the following parts of the paper.

Table 1. Elemental analysis of raw and demineralized Göynük oil shale, \%

\begin{tabular}{|c|c|c|c|c|}
\hline Sample & $\mathrm{N}$ & $\mathrm{C}$ & $\mathrm{S}$ & $\mathrm{H}$ \\
\hline GOS-R & 0.97 & 56.34 & 4.12 & 7.20 \\
GOS-C & 1.19 & 60.00 & 3.96 & 7.63 \\
GOS-N & 1.02 & 59.87 & 4.07 & 7.58 \\
GOS-F & 1.30 & 67.59 & 4.38 & 8.31 \\
\hline
\end{tabular}

\section{Experimental procedure}

\section{Demineralization}

Oil shales were demineralized with $10 \% \mathrm{HCl}, 5 \% \mathrm{HNO}_{3}$ and pure $\mathrm{HF}$, successively under inert atmosphere. $1 \mathrm{~g}$ of sample was stirred with $20 \mathrm{~mL}$ of $10 \% \mathrm{HCl}$ solution. The slurry was stirred for $48 \mathrm{~h}$ under inert atmosphere, thereafter filtered and washed with distilled hot water until the filtrate became neutral. The solid residue was dried under vacuum. Next, $20 \mathrm{~mL}$ of $5 \% \mathrm{HNO}_{3}$ solution were added to $1 \mathrm{~g}$ of pretreated oil shale sample. The slurry was stirred for $1 \mathrm{~h}$ at room temperature. Then it was filtered and washed with distilled hot water until the filtrate became neutral. The solid residue was dried under vacuum. Finally $20 \mathrm{~mL}$ of $\mathrm{HF}$ were added to the residue and this mixture was stirred for $8 \mathrm{~h}$. After being filtered, the demineralized oil shale was washed with distilled hot water and dried under vacuum.

\section{Pyrolysis}

Isothermal pyrolysis of raw and demineralized oil shale samples was performed at $450,500,550,600$ and $650{ }^{\circ} \mathrm{C}$. Reactor $(900 \mathrm{~mm}$ long and 
$50 \mathrm{~mm}$ ID) was constructed from stainless steel S316. $0.5 \mathrm{~g}$ of sample was placed to the sample unit. When pyrolysis system was thermally stable, pyrolysis was started by pulling the piston into downward position to let the sample into the pyrolysis region. The pyrolysis was carried out under a $80 \mathrm{~mL} / \mathrm{min}$ flow of nitrogen. Pyrolysis products were swept out of the reactor and mixed with the reference gas flow $20 \mathrm{~mL} / \mathrm{min}(0.5 \mathrm{vol} . \%$ neopentane in $\mathrm{N}_{2}$ ). The reference gas (neopentane) was not produced as a result of the pyrolysis processing and it was thermally stable under our experimental conditions. Thus, the product evolution rates were calculated on organic carbon basis for each time interval by referring the reference gas peak [12].

The special sampling apparatus was connected to the system at the exit of reactor. The representative samples from pyrolysis products were taken into pre-evacuated glass ampoules at each desired times, the ampoules were sealed by a gas burner and analyzed later by a capillary gas chromatograph with a specially designed system for sample introduction. This sampling technique for gas-vapor multi-component mixture was developed by Schulz et al. [13].

\section{Product analysis}

The pyrolysis products were analyzed by gas chromatography (HP 6890). A temperature-programmed capillary gas chromatograph (between -80 to $250{ }^{\circ} \mathrm{C}$ ) enabled to separate the hydrocarbons $\mathrm{C}_{1}-\mathrm{C}_{25}$ with high resolution. The separation of gas/vapor hydrocarbons mixtures into individual components in the column was achieved in the hydrogen atmosphere using a flame ionization detector. Operating conditions for gas chromatography are given in Table 2.

\section{Table 2. Operating conditions for capillary gas chromatography}

\begin{tabular}{|l|l|}
\hline Gas chromatography & HP 6890 (F. Hewlett Packard) \\
\hline Column & $100 \mathrm{~m} \times 0.25 \mathrm{~mm}$ fused silica \\
Stationary phase & Cross linked methyl siloxane (HP-1) \\
Film thickness & $0.5 \mu \mathrm{m}$ \\
Carrier gas & Hydrogen \\
Detector & Flame ionization (FID) \\
Detector temperature & $350^{\circ} \mathrm{C}$ \\
Injector temperature & $290^{\circ} \mathrm{C}$ \\
& Starting temperature $-80^{\circ} \mathrm{C}$, isothermal $3.5 \mathrm{~min}$ \\
& $30^{\circ} \mathrm{C} /$ min to $-30^{\circ} \mathrm{C}$, isothermal $1 \mathrm{~min}$ \\
Temperature program & $25^{\circ} \mathrm{C} / \mathrm{min}$ to $0^{\circ} \mathrm{C}$, isothermal $2 \mathrm{~min}$ \\
& $10^{\circ} \mathrm{C} / \mathrm{min}$ to $25^{\circ} \mathrm{C}$, isothermal $1 \mathrm{~min}$ \\
& $10^{\circ} \mathrm{C} / \mathrm{min}$ to $250^{\circ} \mathrm{C}$, isothermal $3 \mathrm{~min}$ \\
\hline
\end{tabular}




\section{Result and discussion}

A series of pyrolysis experiments was performed with raw and demineralized oil shale samples in an isothermal pyrolysis (IP) reactor. Pyrolysis products were analyzed by capillary gas chromatography.

The volatile hydrocarbon recovery (VHR) from GOS-R analyzed by our technique was found to be 18.3, 27.1, 35.9, 45.5 and $50.2 \%$ by weight (on carbon basis) at pyrolysis temperatures of $450,500,550,600$ and $650{ }^{\circ} \mathrm{C}$, respectively. The volatile hydrocarbon recoveries from GOS-R, GOS-C, GOS-N and GOS-F are given in Fig. 1. For all samples, as temperature increases, VHR increased. Similar results were obtained in the study made by Sadiki et al. [1] - yields of gaseous products increased with increasing temperature. VHR showed a decrease at pyrolysis of GOS-C compared to pyrolysis of GOS-R. The removal of carbonates caused a slight decrease in volatile hydrocarbon yield. Calcite minerals are known to catalyze degradation of organic structure of coal and oil shale, therefore, removal of these minerals might have changed the behavior of GOS-C resulting in a decrease in VHR relative to GOS-R. This agrees with the results of the study of temperature-programmed pyrolysis of Beypazarı oil shale by Ballice [14]. Alkali and alkaline earth metal cations affect reactivity of oil shales, and leaching of these mineral matters with $\mathrm{HCl}$ slightly decreases oil shale conversion to volatile hydrocarbons and affects the reactivity of organic matter at pyrolysis. Oil shale contains discrete minerals, and substantial amounts of inorganic matter are associated with organics as cations in carboxylic acid salts, such as $\mathrm{COO}-\mathrm{M}^{+}, \mathrm{COO}-\mathrm{M}^{2+} \mathrm{OH}^{-},-(\mathrm{COO})_{2} \mathrm{M}^{2+}$, where $\mathrm{M}^{2+}$ is an alkali or alkaline earth metal cation. IR spectra of the original oil shale samples revealed the presence of a significant amount of acidic groups.

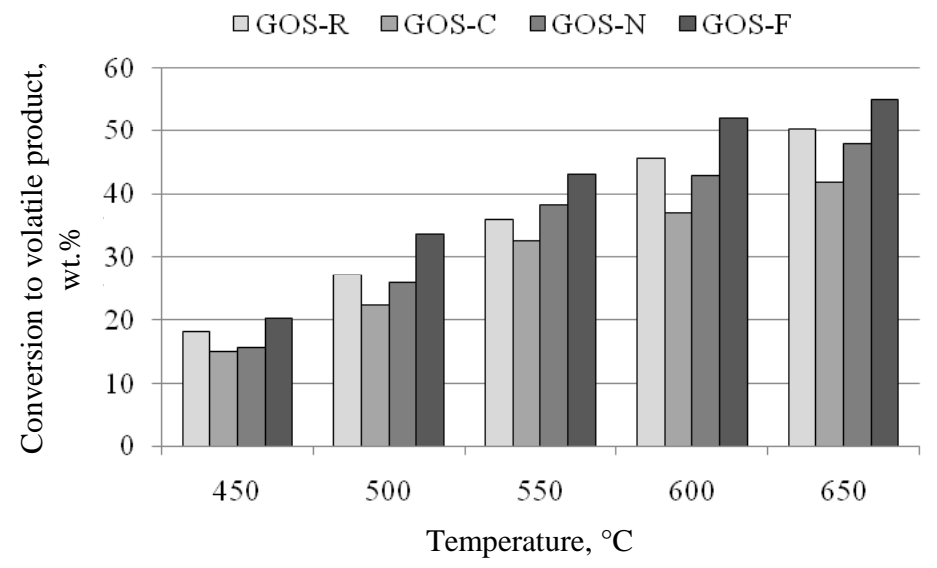

Fig. 1. Volatile fraction of hydrocarbons recovered from GOS-R, GOS-C, GOS-N and GOS-F in the isothermal pyrolysis reactor (on organic carbon basis). 
The inhibition effect of the silicates seemed to be greater than the catalytic effect of calcite minerals in the pyrolysis reactions. The removal of silicates by HF washing of Göynük oil shale caused a change in the production of volatiles. The hydrocarbon yield increased at pyrolysis of silicate-free Göynük oil shale, whereas the deposition of carbon in solid residue decreased [6].

VHR at pyrolysis of GOS-N was increased as compared with GOS-C samples, but less than VHR at pyrolysis of GOS-R. This result shows that removal of material soluble in $\mathrm{HNO}_{3}$ did not affect VHR yield. This result was similar to the study by Metecan et al. [15]. Surprisingly, Karayildirim et al. [11] found that elimination of carbonates did not change activation energy of Göynük oil shale pyrolysis while studying the effect of demineralization. For $\mathrm{HNO}_{3}$-washed samples $E_{A}$ was approximately $54 \%$ higher than the value for initial shale.

Also pyrolysis of demineralized oil shale was investigated by Karabakan et al. [16] to obtain kinetic parameters for the decomposition process. Removal of carbonates caused an increase in the values of activation energies of pyrolysis reactions. This result was in accordance with the reduction of VHR after $\mathrm{HCl}$ washing. At pyrolysis of GOS-F, VHR was increased nearly $10 \%$ compared with the yield for raw oil shale sample. This shows that silicate minerals inhibit conversion to volatile hydrocarbons. According to Karabakan et al., at pyrolysis of HF-washed Göynük oil samples, the increase in percentage of volatiles was about $20 \%$ [16].

The yield of solid residue of GOS-R pyrolysis was determined to be 46.0, $42.3,40.6,39.4$ and $37.3 \%$ by weight at pyrolysis temperatures of 450,500 , 550,600 and $650{ }^{\circ} \mathrm{C}$, respectively. Conversion to the solid residue decreased as the temperature increased (Fig. 2). The amount of the solid residue decreased as a function of temperature. This tendency was explained mainly

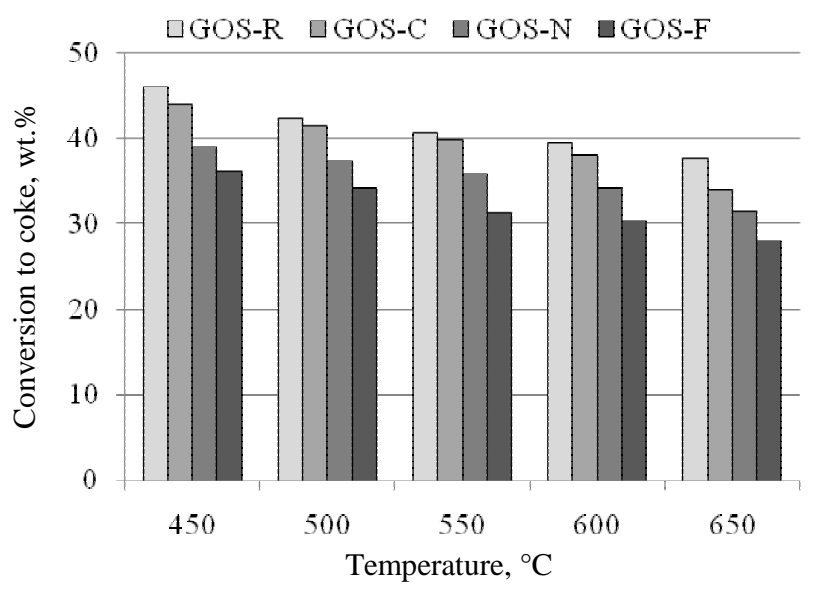

Fig. 2. Conversion of GOS-R, GOS-C, GOS-N, GOS-F to solid residue in the isothermal pyrolysis reactor. 
by deposition of carbon in the solid residue. Aromatic compounds are more prone to undergo coking reactions than aliphatic ones, and the pyrolysis reaction in the presence of silicate showed the catalytic effect of silicate minerals aiding the coking reactions. Similar results were obtained by previous researchers $[12,14,17]$.

For the pyrolysis of GOS-R, total hydrocarbon recoveries (THR) were calculated to be $54.0,57.7,59.4,60.6$ and $62.7 \mathrm{wt} . \%$ at pyrolysis temperatures of $450,500,550,600$ and $650{ }^{\circ} \mathrm{C}$, respectively. Total hydrocarbon recoveries at each pyrolysis temperature were calculated by subtracting coke conversion values from $100 \%$. Total hydrocarbon recoveries at isothermal pyrolysis of GOS-R, GOS-C, GOS-N and GOS-F are shown in Fig. 3. At isothermal pyrolysis of oil shale both the volatile fraction of recovered hydrocarbons (Fig. 1), which can be analyzed by our analytical technique, and total hydrocarbon recovery (Fig. 3) increased with increasing temperature. It can easily be seen that the volatile fraction of recovered hydrocarbons was lower than total hydrocarbon recovery at all pyrolysis temperatures. This denotes that the products of isothermal pyrolysis of oil shale at all pyrolysis temperatures mainly consist of polyaromatics and high-molecularweight hydrocarbons. Lighter hydrocarbons were formed by decomposition of asphaltenes and preasphaltened at increasing temperatures. Conversion of organic carbon to polyaromatics (asphaltenes and preasphaltenes) is given in Fig. 4. The analysis method used in this study did not allow detecting polyaromatics such as preasphaltenes (pyridine-soluble and benzene insoluble materials) and asphaltenes (benzene-soluble and hexane insoluble materials) in the pyrolysis products [14].

During the pyrolysis reaction, carbon-rich solid residue is formed as a byproduct at dehydrogenation of hydrocarbons by way of catalytic and pyrolytic reactions. As the pyrolysis reaction runs, the coke aggregates and accumulates on the solid surface of the asphaltite. It is formed by several

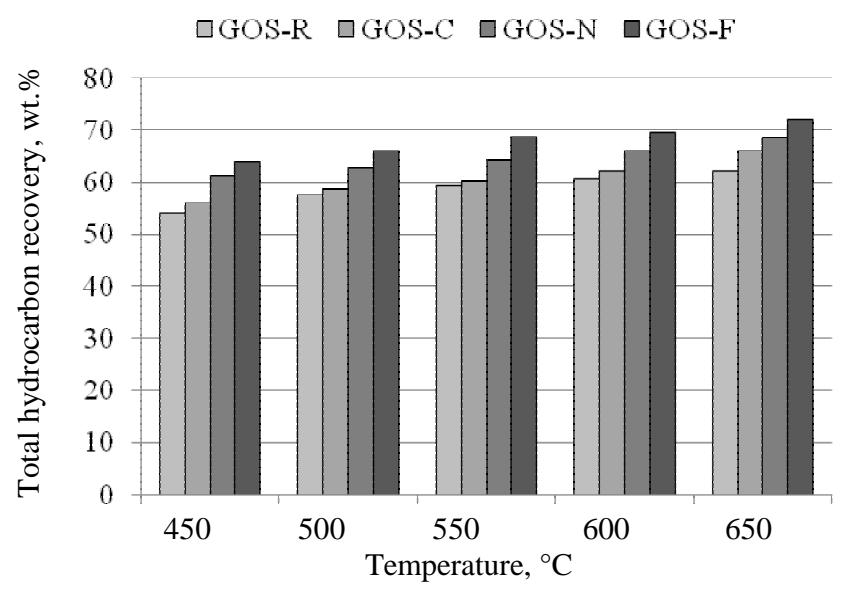

Fig. 3. Total hydrocarbon recovery (THR) from GOS (on total mass basis). 


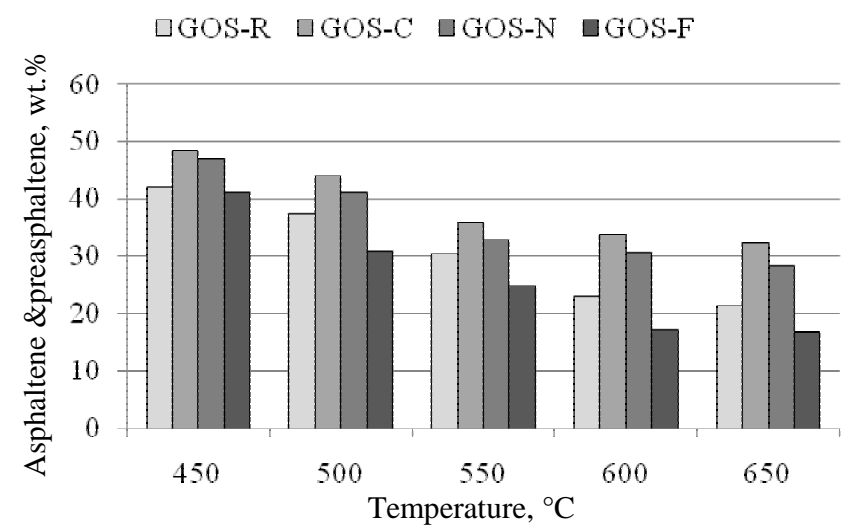

Fig. 4. Conversion level of organic carbon to polyaromatics (asphaltenes \& preasphaltenes).

related mechanisms including dehydrogenation, polymerization and condensation of both light olefinic and heavy aromatic compounds. During thermal cracking, the coke is formed by dehydrogenation of the highly olefinic radicals or the condensation, polymerization, dehydrogenation of the heavy aromatic droplets. In these reactions, the coke precursors play an important role. The typical coke precursors are heavy aromatic droplets like tars, low-molecular-weight hydrocarbons whose molecular weight is below 100 - such as ethylene, butene and so forth, and free radicals such as methyl, ethyl, propyl, benzyl, etc. They affect the type of coke formed and the rate of coke accumulation. Coke formation in the reactor results in reduction of the yields of the main products [18].

Volatile fractions of recovered hydrocarbons analyzed were classified according to their carbon number $-\mathrm{C}_{1}-\mathrm{C}_{4}\left(\right.$ or $\left.\mathrm{C}_{2}-\mathrm{C}_{4}\right), \mathrm{C}_{5}-\mathrm{C}_{9}, \mathrm{C}_{10}-\mathrm{C}_{15}$ and $\mathrm{C}_{16+}$. To understand the effect of mineral matter on carbon conversion, the distribution ratios of $n$-paraffins and 1-olefins were calculated for all temperatures and oil shale samples. The distribution of $n$-parafins and 1-olefins in shale oil are given in Figures 5 and 6. The distribution $\mathrm{C}_{1}-\mathrm{C}_{4}$ $\left(\mathrm{C}_{2}-\mathrm{C}_{4}\right)$ in pyrolysis products was increased after demineralization of GOS-R with $\mathrm{HCl}$. Comparison of the distribution of $n$-parafins and 1-olefins shows that evolution of products was clearly increased by removing carbonate minerals form organic matter. It indicates that pyrolysis reactions were catalyzed by alkaline earth metal cations in carbonates and inhibited by silicates, and the inhibition effect of silicates seems to be greater than the catalytic effect of carbonates in the pyrolysis reactions [14].

As for light fractions of $n$-paraffins and 1-olefins, their yield increased after $550{ }^{\circ} \mathrm{C}$ for all samples. This may be explained by decomposition of heavier fractions. But just for GOS-F sample, the yield of $\mathrm{C}_{1}-\mathrm{C}_{4}\left(\mathrm{C}_{2}-\mathrm{C}_{4}\right)$ decreased at $650{ }^{\circ} \mathrm{C}$ compared with the yield at $600{ }^{\circ} \mathrm{C}$. The reason may be polymerization reaction of $\mathrm{C}_{1}-\mathrm{C}_{4}\left(\mathrm{C}_{2}-\mathrm{C}_{4}\right)$ groups. The increase in the yield of $\mathrm{C}_{5}-\mathrm{C}_{9}$ and $\mathrm{C}_{10}-\mathrm{C}_{15}$ groups proves this result. 


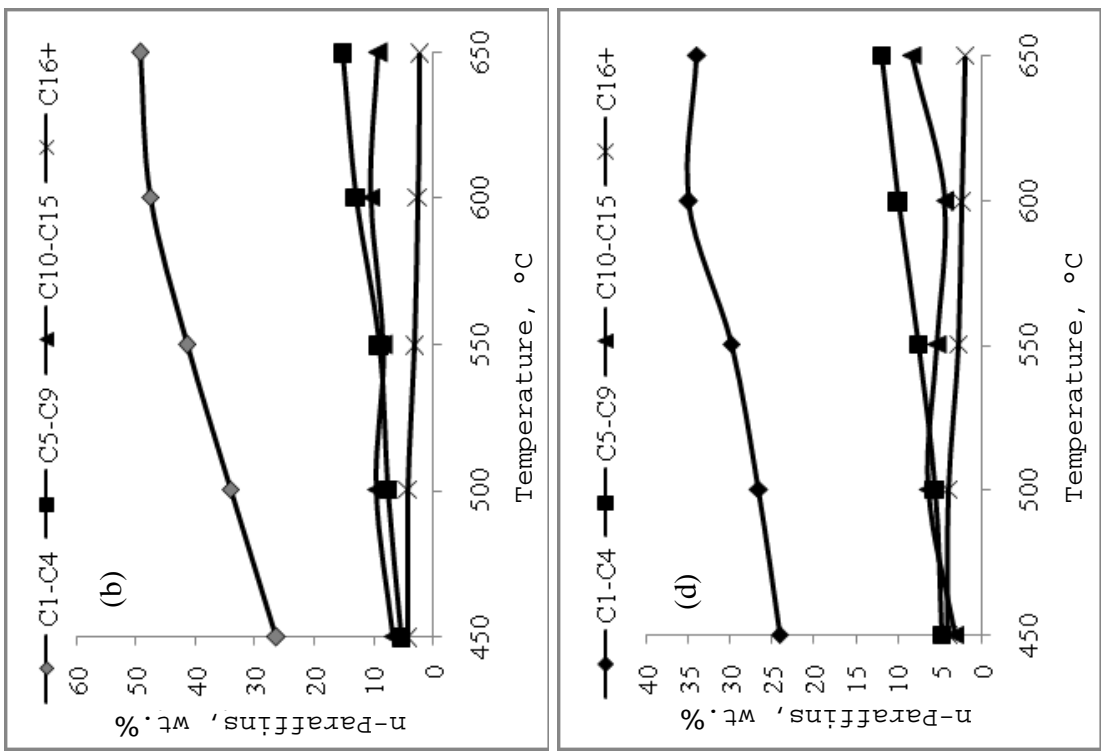

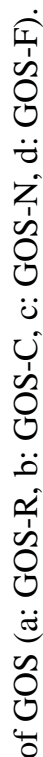

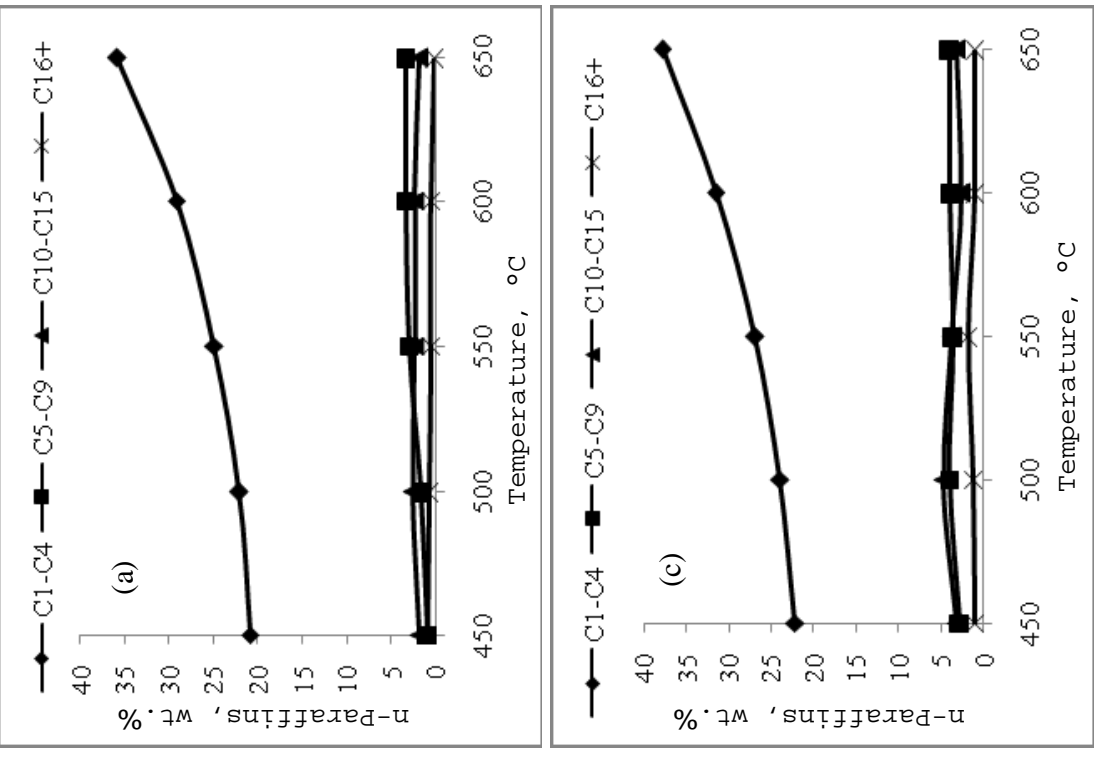

告 


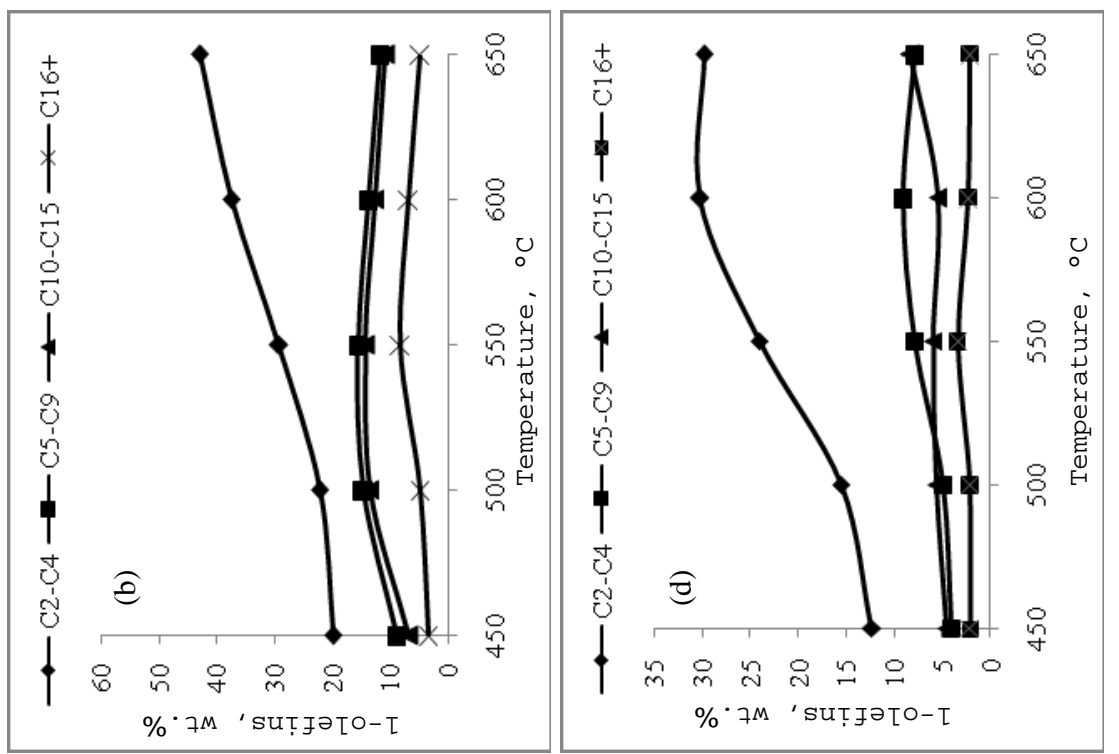

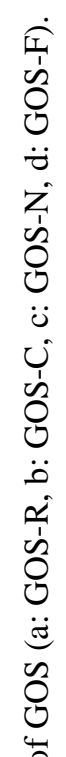
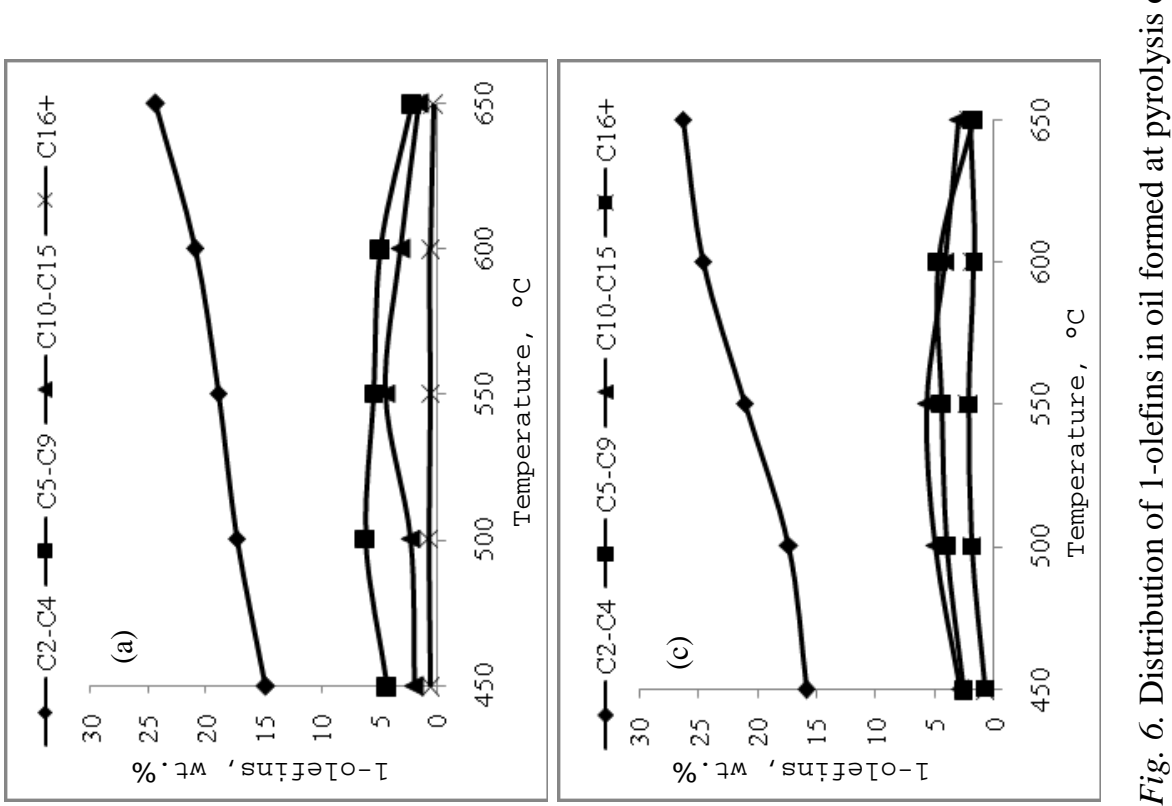


\section{Conclusions}

Göynük oil shale was demineralized with $\mathrm{HCl}, \mathrm{HNO}_{3}$ and $\mathrm{HF}$ successively. The effect of mineral matter on pyrolysis products was investigated. VHR and THR of GOS-R, GOS-C, GOS-N and GOS-F were increased with increasing temperature. Increasing temperature decreased the weight $\%$ of asphaltenes and preasphaltenes in volatile hydrocarbons. VHR yield of GOS-C is less than that of the GOS-R, GOS-N and GOS-F. This can be explained by alkali groups having catalytic effect on carbon conversion. In the absence of pyrite, recovery of volatile hydrocarbons slightly decreased when compared with GOS-R. So, treating oil shale with $\mathrm{HNO}_{3}$ has no important role on VHR. Removing silicates increased the recovery of hydrocarbon yield of oil shales. This can be explained by inhibition effect of the silicates. The yield of $n$-paraffins is greater than the yield of 1-olefins.

$\begin{array}{ll}\text { Abbreviations } & \\ \text { GOS-R : } & \text { Raw oil shale } \\ \text { GOS-C : } & \text { GOS-R demineralized with } \mathrm{HCl} \\ \text { GOS-N : } & \text { GOS-C demineralized with } \mathrm{HNO}_{3} \\ \text { GOS-F : } & \text { GOS-N demineralized with } \mathrm{HF} \\ \text { VHR }: & \text { volatile hydrocarbon recovery } \\ \text { THR }: & \text { total hydrocarbon recovery }\end{array}$

\section{REFERENCES}

1. Sadiki, A., Kaminsky, W., Halim,H., Bekri, O. Fluidised bed pyrolysis of Moroccan oil shales using the hamburg pyrolysis process // J. Anal. Appl. Pyrol. 2003. Vol. 70, No. 2. P. 427-435.

2. Kok, M. V., Senguler, I., Hufnagel, H., Sonel, N. Thermal and geochemical investigation of Seyitomer oil shale// Thermochim. Acta. 2001.Vol. 371, No. 1-2. P. 111-119.

3. Şener, M., Şengüler, $\dot{I}$. Geological, mineralogical and geochemical characteristics of oil shale bearing deposits in the Hatıldağ oil shale field, Göynük, Turkey // Fuel. 1998. Vol. 77, No. 8. P. 871-880.

4. Sert, M., Ballice, L., Yuksel, M., Saglam, M., Reimert, R., Erdem, S. Effect of solvent swelling on pyrolysis of kerogen (type-1) isolated from Göynük oil shale Turkey // J. Anal. Appl. Pyrol. 2009. Vol. 84, No. 1. P. 31-38.

5. Subasinghe, N. D., Awaja, F., Bhargava, S. K. Variation of kerogen content and mineralogy in some Australian tertiary oil shales // Fuel. 2009. Vol. 88, No. 2. P. 335-339.

6. Ballice, L. Stepwise chemical demineralization of Göynük (Turkey) oil shale and pyrolysis of demineralization products // Ind. Eng. Chem. Res. 2006. Vol. 45, No. 3. P. 906-912. 
7. Trewhella, M. J., Poplett, J. F., Grint, A. Structure of Green River oil shale kerogen: Determination using solid state ${ }^{13} \mathrm{C}$ n.m.r. spectroscopy // Fuel. 2006. Vol. 65, No. 4. P. 541-546.

8. Patterson, J. H. A review of the effects of minerals in processing of Australian oils shales // Fuel. 1994. Vol.73, No. 3. P. 321-327.

9. Saxby, J. D. Isolation of kerogen in sediments by chemical methods // Chem. Geol. 1970. Vol. 6. P. 173-184.

10. Larsen, J. W., Pan, C. S., Shawer, S. Effect of demieralization on the macromolecular structure of coals // Energy \& Fuels. 1989. Vol. 3, No. 5. P. 557-561.

11. Karayıldırım, T., Yanik, J., Yuksel, M., Saglam, M. Thermogravimetric analysis of pretreated Göynük oil shale and Şırnak asphaltite // Oil Shale. 2004. Vol. 21, No. 3. P. 205-216.

12.Sert, M., Ballice, L., Yuksel,M., Saglam,M. Erdem, S. Fast pyrolysis Şırnak asphaltite (Turkey) and characterization of pyrolysis products // Energy Sources, Part A. 2008. Vol. 30, No. 8. P. 671-680.

13.Schulz, H., Böhringer, W., Kohl, C., Rahmen, N., Will, A. DGMK-Forschungsbericht 320 DGMK. - Hamburg, Germany, 1984.

14. Ballice, L. Effect of demineralization on yield and composition of the volatile products evolved from temperature-programmed pyrolysis of Beypazari (Turkey) oil shale // Fuel Process. Technol. 2005. Vol. 86, No. 6. P. 673-690.

15.Metecan, I. H., Saglam, M.,Yanik, J., Ballice, L., Yuksel, M. The effect of pyrite catalyst on the hydroliquefaction of Göynük (Turkey) oil shale in the presence of toluene // Fuel. 1999. Vol. 78, No. 5. P. 619-622.

16. Karabakan, A., Yurum, $Y$. Effect of the mineral matrix in the reactions of oil shales: 1. Pyrolysis reactions of Turkish Göynük and US Green River oil shales // Fuel. 1998. Vol. 77, No. 12. P. 1303-1309.

17. Salepcioglu, S., Gungoren, T., Sert, M., Erdem, S., Saglam, M., Yuksel,M., Ballice, $L$. Classification of volatile products evolved at fast co-pyrolysis of Göynük oil shale with low density polyethylene // Oil Shale. 2008. Vol. 25, No. 3. P. 335-347.

18. Kopinke, F. D., Zimmermann, G., Nowak, S. On the mechanism of coke formation in steam cracking - conclusions from results obtained by tracer experiments // Carbon. 1988. Vol. 26, No. 2. P. 117-124.

Presented by M. V. Kök

Received June 16, 2009 